\title{
Which population level environmental factors are associated with asthma, rhinoconjunctivitis and eczema? Review of the ecological analyses of ISAAC Phase One
}

M Innes Asher ${ }^{1 *}$, Alistair W Stewart ${ }^{2}$, Javier Mallol ${ }^{3}$, Stephen Montefort ${ }^{4}$, Christopher KW Lai $^{5}$, Nadia Aït-Khaled ${ }^{6}$, Joseph Odhiambo ${ }^{7}$, The ISAAC Phase One Study Group ${ }^{8}$

\begin{abstract}
The International Study of Asthma and Allergies in Childhood (ISAAC) Phase One showed large worldwide variations in the prevalence of symptoms of asthma, rhinoconjunctivitis and eczema, up to 10 to 20 fold between countries. Ecological analyses were undertaken with ISAAC Phase One data to explore factors that may have contributed to these variations, and are summarised and reviewed here.

In ISAAC Phase One the prevalence of symptoms in the past 12 months of asthma, rhinoconjunctivitis and eczema were estimated from studies in 463,801 children aged 13 - 14 years in 155 centres in 56 countries, and in 257,800 children aged 6-7 years in 91 centres in 38 countries. Ecological analyses were undertaken between symptom prevalence and the following: Gross National Product per capita (GNP), food intake, immunisation rates, tuberculosis notifications, climatic factors, tobacco consumption, pollen, antibiotic sales, paracetamol sales, and outdoor air pollution.

Symptom prevalence of all three conditions was positively associated with GNP, trans fatty acids, paracetamol, and women smoking, and inversely associated with food of plant origin, pollen, immunisations, tuberculosis notifications, air pollution, and men smoking. The magnitude of these associations was small, but consistent in direction between conditions. There were mixed associations of climate and antibiotic sales with symptom prevalence. The potential causality of these associations warrant further investigation. Factors which prevent the development of these conditions, or where there is an absence of a positive correlation at a population level may be as important from the policy viewpoint as a focus on the positive risk factors. Interventions based on small associations may have the potential for a large public health benefit.
\end{abstract}

\section{What was ISAAC Phase One?}

The International Study of Asthma and Allergies in Childhood (ISAAC) Phase One studied symptom prevalence and severity of asthma, rhinoconjunctivitis and eczema between populations around the world to elucidate factors influencing these conditions. This multicentre cross-sectional study was undertaken between 1992 and 1997 using standardised methodology with subjects being school children from schools which were randomly sampled within centres [1]. Two age groups

\footnotetext{
* Correspondence: mi.asher@auckland.ac.nz
'Department of Paediatrics: Child and Youth Health, The University of

* Correspondence: mi.asher@auckland.ac.nz
'Department of Paediatrics: Child and Youth Health, The University of Auckland, Auckland, New Zealand
} target sample size of 3,000 children per age group per centre. Simple written questionnaires were self-completed by the 13-14 year old participants, and by the parents of the 6-7 year old participants. These questionnaires were translated from English into a local language where appropriate. An optional video asthma questionnaire was delivered to the 13-14 year age group, with verbal instructions in the local language. The participation rates averaged $92 \%$ for the 13-14 year age group and $89 \%$ for the 6-7 year age group. The findings of large variations in the symptom prevalence of asthma, rhinoconjunctivitis and eczema, up to 10 to 20 fold 
between countries, around the world [2-5] suggested that environmental rather than genetic factors may be most influential.

One of the scientific driving forces behind the ISAAC collaboration was the suspicion that causes of asthma in high prevalence countries might be so widespread that it would be difficult if not impossible to detect them by comparisons between individuals within those countries. The very large number of participating centres (156) and countries (56) in ISAAC Phase One was an ideal opportunity to look at potential causes between populations. Ecological analyses are an appropriate method to do this to generate hypotheses which may explain these variations. Thus ecological analyses were undertaken with ISAAC Phase One symptom prevalence estimates, using a wide range of data sources at a population level, on a variety of environmental topics [6-17]. The findings for the potentially protective or risk factors examined which are relevant for asthma, rhinoconjunctivitis and eczema are reviewed and interpreted in this paper.

\section{What ecological analyses were undertaken?}

Ecological analyses were undertaken with ISAAC Phase One symptom prevalence data for asthma, rhinoconjunctivitis and eczema with environmental data from existing sources. In some cases environmental data was unavailable for all centres or countries. The effect of country level economic development was examined using the 1993 Gross National Product per capita (GNP) as reported by the World Bank for all 156 centres in 56 countries involved in Phase One [14]. Dietary factors were assessed using Food and Agriculture Organization FAOSTAT food balance sheets for 1995 in 53 countries. Food produced and imported, less food exported gave the country supply of food from which was estimated the per capita supply of food [9]. Associations with consumption of trans fatty acids were assessed in 55 centres in 10 European countries using data from 1999 [17]. Immunisation rates at a national level were obtained from the World Health Organization (WHO) for 56 countries, and immunisation rates at a centre level were obtained through ISAAC Principal Investigators in 92 ISAAC centres for vaccines against diphtheria, tetanus, pertussis, BCG and measles [7]. The years selected for the immunisation data (1982 for the 13-14 year age group and 1989 for the 6-7 year age group) approximately corresponded to the year of birth of the participants. Tuberculosis (TB) exposure was assessed in two ways - firstly using notification rates from WHO data for 1980-1982 in 23 countries for the 13-14 year age group at the time when the older age group would have been infants [15]; secondly from WHO TB estimated incidence for the 6-7 year age group in 38 countries and 55 countries for the 13-14 year age group in 1995, the mean year of the data collection for the older age group [13]. Climatic factors were assessed using data from the World Weather Guide and derived variables for 146 ISAAC centres [16] and a subset of 57 centres in 12 countries in Western Europe. Tobacco exposure was assessed using WHO data for tobacco consumption per capita 1990-1992, and tobacco smoking prevalence in women and tobacco smoking in men in 155 centres from 56 countries [11]. Pollen exposure was assessed using data for pollen counts, and duration and severity of pollen seasons in 28 centres in 11 countries for 1995 [8]. Associations with antibiotic use was assessed using data for antibiotic sales for 28 countries from International Medical Statistics, Health Global Services, United Kingdom 1995 [10]. Air pollution was assessed for 105 centres in 51 countries using the World Bank Global Model on Ambient Particulates for 1999 which estimated annual concentrations for all cities with populations of more than 100,000 [6]. Paracetamol exposure was assessed using data for paracetamol sales per capita in 106 centres [12].

Each analysis is described in detail elsewhere [6-17]. For all analyses mixed model regression analyses were carried out to incorporate the country and centre structure of the data sets, except trans fatty acids where linear regressions were used. ISAAC data was at the centre level, but most environmental data sets represented whole countries, therefore mostly country level was used in the analyses as specified in the source articles. Exceptions were air pollution and climate which could be analysed at centre (city) level. A variety of measures of association were used for the analyses such as Spearman rank correlation coefficient, and the statistical significance level used was $p<0.05$. Non-statistically significant trends were noted where they were consistent with significant findings. The analyses did not examine combinations and interactions of the variables.

As GNP was found to have a weak positive association with symptom prevalence [14], the analyses of other environmental factors were repeated with GNP in the model. The findings presented in this paper pertain to analyses adjusted for GNP, but not adjusted for any other variables. Although the published papers analysed most of the ISAAC questions, this paper reviews only the analyses of symptoms in the past 12 months of asthma, rhinoconjunctivitis and eczema.

\section{What were the key findings?}

The ecological analyses in both age groups demonstrated mostly weak relationships of small magnitude between environmental variables and current symptoms of asthma, rhinoconjunctivitis and eczema, or no association at all. The results are summarised in Table 1, Table 2 and Table 3. Where associations were found 
these were generally in the same direction for all three conditions, but were statistically significant for only some associations $[6-9,11,12,14,17]$. A weak positive association was found between asthma and eczema symptoms and GNP. Weak positive associations were found between symptom prevalence and tobacco consumption, smoking by women, trans fatty acids and paracetamol. Weak inverse associations were found for plant-based foods, immunisation for DTP and measles, tuberculosis incidence pollen exposure, smoking by men. A mixed pattern of associations were found for antibiotic sales and climate. For air pollution, in those countries with more than one centre, the association was weakly positive, in contrast to the weakly negative association at country level.

\section{What do these findings mean? - methodological issues}

This is the first large worldwide analysis of protective and risk factors related to asthma, rhinoconjunctivitis and eczema in children between populations. Standardised methodology was used to estimate the 12 month period prevalence of symptoms of the three conditions. The recall of 12 month symptoms is a more accurate

Table 1 Symptoms of wheeze in the past 12 months - summary of ecological analyses*.

\begin{tabular}{|c|c|c|c|c|c|c|c|}
\hline \multirow[t]{3}{*}{ Ecological Issue } & \multirow[t]{3}{*}{ Specific Factor } & \multicolumn{4}{|c|}{ 13-14 Year Age Group } & \multirow{2}{*}{\multicolumn{2}{|c|}{$\begin{array}{c}\text { 6-7 Year Age Group } \\
\text { Written Questionnaire }\end{array}$}} \\
\hline & & \multicolumn{2}{|c|}{ Written Questionnaire } & \multicolumn{2}{|c|}{ Video Questionnaire } & & \\
\hline & & $\begin{array}{c}\text { Direction of } \\
\text { effect }\end{array}$ & $\begin{array}{c}\mathrm{P} \\
\text { Value }\end{array}$ & $\begin{array}{c}\text { Direction of } \\
\text { effect }\end{array}$ & $\begin{array}{c}\mathrm{P} \\
\text { Value }\end{array}$ & $\begin{array}{c}\text { Direction of } \\
\text { effect }\end{array}$ & $\begin{array}{c}P \\
\text { value }\end{array}$ \\
\hline $\begin{array}{l}\text { Economic } \\
\text { development }\end{array}$ & GNP & + & 0.007 & + & 0.08 & + & 0.84 \\
\hline \multirow[t]{6}{*}{$\overline{\text { Diet }}$} & Calories from cereals and rice $\%$ & - & 0.0005 & - & 0.07 & - & 0.021 \\
\hline & Protein from cereals and nuts $\%$ & - & 0.002 & - & 0.015 & - & 0.062 \\
\hline & Starch g/day & - & 0.008 & - & 0.01 & - & 0.036 \\
\hline & Vegetables $\mathrm{g} / \mathrm{d}$ & - & 0.041 & - & 0.205 & - & 0.262 \\
\hline & Vegetable Vitamin A $\mu / d$ & - & 0.04 & - & 0.159 & - & 0.235 \\
\hline & Trans fatty acids & + & $<0$ & + & $<0.05$ & & \\
\hline \multirow[t]{2}{*}{ Immunisation } & Local immunisation rates for DTP\# & - & 0.047 & & & - & $>0.05$ \\
\hline & Local immunisation rates for measles & - & $>0.05$ & & & - & $>0.05$ \\
\hline \multirow[t]{2}{*}{ TB exposure } & TB notification rates & - & 0.344 & - & 0.018 & & \\
\hline & Estimated TB incidence rates & - & 0.262 & - & 0.263 & - & $\begin{array}{c}< \\
0.0001\end{array}$ \\
\hline \multirow[t]{6}{*}{ Outdoor climate } & Altitude & - & $>0.05$ & + & $>0.05$ & - & $>0.05$ \\
\hline & Annual variation in mean temperature & - & $>0.05$ & - & $>0.05$ & - & $>0.05$ \\
\hline & Lowest monthly mean temperature & + & $>0.05$ & 0 & $>0.05$ & + & $>0.05$ \\
\hline & Annual variation in mean relative humidity & - & $>0.05$ & + & $>0.05$ & - & $>0.05$ \\
\hline & Lowest monthly mean relative humidity & 0 & $>0.05$ & - & $>0.05$ & 0 & $<0.05$ \\
\hline & $\begin{array}{l}\text { Mean relative humidity of } \geq 1 \text { month }< \\
50 \% \text { humidity }\end{array}$ & + & $>0.05$ & + & $>0.05$ & + & $>0.05$ \\
\hline \multirow[t]{2}{*}{ Indoor climate } & Mean annual relative humidity & 0 & $>0.05$ & - & $>0.05$ & - & $>0.05$ \\
\hline & Lowest monthly mean relative humidity & + & $>0.05$ & 0 & $>0.05$ & 0 & $>0.05$ \\
\hline \multirow[t]{3}{*}{ Tobacco smoking } & Tobacco consumption, $\geq 15$ yrs & 0 & 0.92 & + & 0.53 & + & 0.46 \\
\hline & Tobacco smoking, women & + & 0.06 & + & 0.72 & + & 0.32 \\
\hline & Tobacco smoking, men & - & 0.001 & - & 0.004 & - & 0.06 \\
\hline \multirow[t]{2}{*}{ Pollen } & Total grass pollen count & - & 0.67 & & & & \\
\hline & Days with high pollen counts & - & 0.39 & & & & \\
\hline Antibiotic usage & Antibiotic sales per capita & - & 0.21 & + & 0.01 & & \\
\hline Air pollution & $\mathrm{PM}_{10}$ & - & 0.03 & & & - & 0.06 \\
\hline Paracetamol & Per capita paracetamol sales & + & $\begin{array}{c}< \\
0.0005\end{array}$ & & & + & 0.001 \\
\hline
\end{tabular}

*standardized for GNP. Where $p$ values are recorded as $>0.05$ the non significant $p$ values were not provided in the source publication. \#DTP $=$ Diphtheria and tetanus toxoids and pertussis.

Blank space $=$ data not collected. $+=$ positive association. $-=$ inverse association. $0=$ no association. 
Table 2 Symptoms of rhinoconjunctivitis in the past 12 months - summary of ecological analyses*.

\begin{tabular}{|c|c|c|c|c|c|}
\hline \multirow[t]{2}{*}{ Ecological Issue } & \multirow[t]{2}{*}{ Specific Factor } & \multicolumn{2}{|c|}{ 13-14 Year Age Group } & \multicolumn{2}{|c|}{ 6-7 Year Age Group } \\
\hline & & Direction of effect & P Value & Direction of effect & $P$ Value \\
\hline Economic development & GNP & + & 0.12 & 0.06 & 0.32 \\
\hline \multirow[t]{6}{*}{ Diet } & Calories from cereals and rice $\%$ & - & 0.007 & - & 0.083 \\
\hline & Protein from cereals and nuts $\%$ & - & 0.039 & - & 0.111 \\
\hline & Starch $\mathrm{g} / \mathrm{d}$ & - & 0.266 & - & 0.069 \\
\hline & Vegetables $\mathrm{g} / \mathrm{d}$ & - & 0.083 & - & 0.453 \\
\hline & Vegetable Vitamin A $\mu / d$ & - & 0.085 & - & 0.479 \\
\hline & Trans fatty acids & + & $<0.0001$ & & \\
\hline \multirow[t]{2}{*}{ Immunisation } & Local immunisation rates for DTP\# & + & 0.002 & - & $>0.05$ \\
\hline & Local immunisation rates for measles & - & 0.015 & - & $>0.05$ \\
\hline TB exposure & TB notification rates, WHO & - & 0.015 & & \\
\hline \multirow[t]{6}{*}{ Outdoor climate } & Altitude & - & $>0.05$ & - & $>0.05$ \\
\hline & Annual variation in mean temperature & - & $>0.05$ & - & $>0.05$ \\
\hline & Lowest monthly mean temperature & + & $>0.05$ & + & $>0.05$ \\
\hline & Annual variation in mean relative humidity & + & $>0.05$ & - & $>0.05$ \\
\hline & Lowest monthly mean relative humidity & - & $>0.05$ & - & $>0.05$ \\
\hline & Mean relative humidity of $\geq 1$ month $<50 \%$ humidity & + & $>0.05$ & + & $>0.05$ \\
\hline \multirow[t]{2}{*}{ Indoor climate } & Mean annual relative humidity & + & $>0.05$ & + & $>0.05$ \\
\hline & Lowest monthly mean relative humidity & + & $>0.05$ & + & $>0.05$ \\
\hline \multirow[t]{3}{*}{ Tobacco smoking } & Tobacco consumption, $\geq 15$ yrs & - & 0.86 & + & 0.52 \\
\hline & Tobacco smoking, women & - & 0.68 & + & 0.76 \\
\hline & Tobacco smoking, men & - & $<0.001$ & - & 0.06 \\
\hline \multirow[t]{2}{*}{ Pollen } & Total grass pollen count & - & 0.07 & & \\
\hline & Days with high pollen counts & - & 0.14 & & \\
\hline Antibiotic usage & Antibiotic sales per capita & - & 0.76 & & \\
\hline Air pollution & $\mathrm{PM}_{10}$ & - & 0.49 & - & 0.06 \\
\hline Paracetamol & Per capita paracetamol sales & + & $<0.0005$ & + & 0.002 \\
\hline
\end{tabular}

*standardized for GNP. Where $\mathrm{p}$ values are recorded as $>0.05$ the non significant $\mathrm{p}$ values were not provided in the source publication. \#DTP = Diphtheria and tetanus toxoids and pertussis.

Blank space $=$ data not collected. $+=$ positive association. $-=$ inverse association.

assessment of disease than diagnostic labelling which is subject to recall bias and different diagnostic fashions especially in such diverse parts of the world.

As country level environmental data was used most commonly (because centre-level data was unavailable) associations at the country level may have introduced complex biases when analysed against centre-level symptoms, and thus some caution is required in the interpretation of the results. This is illustrated by the contrasting results for air pollution.

The global coverage of ISAAC is advantageous in terms of scope and size for ecological analyses, making them potentially more robust than smaller less representative studies. Multiple languages were used which raises the possibility of population level confounding. However the variations in prevalence of asthma from the written questionnaire were similar in their global distribution to the prevalence from the video questionnaire [2]. Furthermore recent analysis suggests that translations of the written questionnaire are reasonably accurate [18], and several of the papers have reported consistent findings for within-region or within-language comparisons which is reassuring. The most robust comparisons, from this viewpoint, are those based on comparisons between centre-level symptom prevalence values and centre level environmental exposures as occurred for the air pollution [6] and immunisation [7] analyses. Further, the results of parental responses for the younger children were similar to those of the responses from the older children.

The ecological approach attempted to find factors which explained the large international variation, but we are unable to tell which factors are relevant to asthma causation. For example if everyone smoked then smoking wouldn't explain any of the international variation, even if it was an important risk factor for asthma (although if there was a strong dose response an effect might be found). It is not appropriate to compare the 
Table 3 Symptoms of eczema in the past 12 months - summary of ecological analyses*.

\begin{tabular}{|c|c|c|c|c|c|}
\hline \multirow[t]{2}{*}{ Ecological Issue } & \multirow[t]{2}{*}{ Specific Factor } & \multicolumn{2}{|c|}{ 13-14 Year Age Group } & \multicolumn{2}{|c|}{ 6-7 Year Age Group } \\
\hline & & Direction of effect & P Value & Direction of effect & $\mathrm{P}$ Value \\
\hline Economic development & GNP & + & 0.05 & + & 0.02 \\
\hline \multirow[t]{6}{*}{ Diet } & Calories from cereals and rice $\%$ & - & 0.246 & - & 0.767 \\
\hline & Protein from cereals and nuts \% & - & 0.028 & - & 0.07 \\
\hline & Starch $\mathrm{g} / \mathrm{d}$ & - & 0.560 & - & 0.058 \\
\hline & Vegetables $\mathrm{g} / \mathrm{d}$ & - & 0.001 & - & 0.157 \\
\hline & Vegetable Vitamin A $\mu / d$ & - & 0.001 & - & 0.153 \\
\hline & Trans fatty acids & + & $<0.0001$ & & \\
\hline \multirow[t]{2}{*}{ Immunisation } & Local immunisation rates for DTP\# & - & 0.048 & - & $>0.05$ \\
\hline & Local immunisation rates for measles & - & 0.036 & - & $>0.05$ \\
\hline TB exposure & TB notification rates, WHO & + & 0.544 & & \\
\hline \multirow[t]{7}{*}{ Outdoor climate } & Latitude & 0 & $>0.05$ & + & $>0.05$ \\
\hline & Altitude & + & $>0.05$ & + & $>0.05$ \\
\hline & Mean annual temperature & - & $>0.05$ & - & $>0.05$ \\
\hline & Annual variation in mean temperature & + & $<0.05$ & + & $>0.05$ \\
\hline & Lowest monthly mean temperature & - & $>0.05$ & - & $<0.05$ \\
\hline & Annual variation in mean relative humidity & - & $>0.05$ & - & $>0.05$ \\
\hline & Lowest monthly mean relative humidity & - & $>0.05$ & - & $>0.05$ \\
\hline \multirow[t]{2}{*}{ Indoor climate } & Mean annual relative humidity & - & $>0.05$ & - & $<0.05$ \\
\hline & Lowest monthly mean relative humidity & 0 & $>0.05$ & - & $>0.05$ \\
\hline \multirow[t]{3}{*}{ Tobacco smoking } & Tobacco consumption, $\geq 15$ yrs & + & 0.35 & + & 0.87 \\
\hline & Tobacco smoking, women & + & 0.42 & + & 0.17 \\
\hline & Tobacco smoking, men & - & 0.007 & - & 0.67 \\
\hline \multirow[t]{2}{*}{ Pollen } & Total grass pollen count & - & 0.15 & & \\
\hline & Days with high pollen counts & - & 0.32 & & \\
\hline Antibiotic usage & Antibiotic sales per capita & - & 0.46 & & \\
\hline Air pollution & $\mathrm{PM}_{10}$ & - & 0.07 & - & 0.10 \\
\hline Paracetamol & Per capita paracetamol sales & + & $<0.0005$ & + & 0.001 \\
\hline
\end{tabular}

size of the correlation coefficients, as the methods for calculating these distort the effects, so that the magnitude of effect cannot be interpreted from them [19]. Notwithstanding these caveats, there are plausible mechanisms for each association (discussed below), suggesting that various factors associated with human development may be affecting variations in symptom prevalence between populations.

Explaining patterns of diseases across the world one variable at a time may be fraught with difficulties, as different factors are likely to be more important in different regions of the world. For example, climate may be important in countries where there is variation in temperature and humidity, and TB exposure will be of potential importance where TB occurs, and not where it doesn't occur. It is also likely that these diseases are multi component diseases, i.e. 3 or more factors need to be present before disease may become manifest, but that level of analysis has not been undertaken.

\section{Economic factors}

The associations observed suggest that economic development of a country may bring with it changes influencing asthma, rhinoconjunctivitis and eczema [14]. Further supportive evidence of this association was found recently in ISAAC Phase Three where data from 98 countries showed that the prevalence of asthma symptoms showed a positive relationship with Gross National Income (GNI), although the prevalence of severe symptoms correlated inversely with GNI [20]. However caution should be used in interpreting the findings because of the great inequalities in income distribution within almost all countries in developing regions of the world. GNP represents the total economic activity of the country, reflecting mean wealth rather 
than median wealth. Thus countries with a highly skewed income distribution due to concentration of wealth in the hands of a small fraction of the population may have a relatively high per capita GNP while the majority of citizens have a relatively low level of income [21]. A further consideration is that GNP does not measure factors that affect quality of life, such as the quality of the environment.

\section{Diet}

Dietary patterns have changed rapidly with modernisation or westernisation, and the associated move away from plant-based foods and addition of man-made fats might affect symptom prevalence. No associations were found for meat, and milk, but showed a pattern of inverse association between plant-based food and symptoms of the three conditions [9]. A protective effect of plant-based food might be mediated through effects on intestinal microflora which are necessary for maturation of Th1 immunity [22]. A further mechanism may be mediated through antioxidant content. This is corroborated by the positive association found between the prevalence of symptoms of asthma, and paracetamol sales [12,23], and more recent work showing associations between symptoms of all three conditions and paracetamol use [23]. The analysis in European countries of trans fatty acids found a positive association, suggesting that man-made fats may be a factor in the prevalence of the three conditions [17].

\section{Tobacco}

The picture which emerged for tobacco was mixed with no association observed with country tobacco consumption [11]. However there was generally a positive relationship between women smoking and the three conditions, yet an inverse association between men smoking and the three conditions. This analysis indicates that the well established individual level association between parental cigarette smoking and asthma does not account for the international differences in asthma prevalence.

\section{Tuberculosis}

The inverse association found between asthma symptom prevalence and estimated TB incidence [13] and actual TB notifications rates [15] supports other evidence that exposure to Mycobacterium tuberculosis may reduce the risk of developing asthma. This may occur through induction of Th1 type immune responses. The implications of this relationship in the changing world of TB disease (the increase in AIDS and the concomitant increase in TB cases in Africa and the decrease of TB in other regions such as Latin America) need further study. Immunisation

Two levels of immunisation analyses were undertaken: country level, and centre level. The country level analyses showed no associations [7]. The more powerful centre-level analyses showed small inverse relationships between DTP and measles in the older age group only, with no associations with BCG. In view of earlier reports that immunisation might be a risk factor for asthma, this mainly null result is reassuring for population immunisation programmes, given their importance for child health.

\section{Antibiotics}

The relationships between symptom prevalence and antibiotic exposure was not clear cut. A mixture of weak inverse and positive effects were found between symptom prevalences and total antibiotic sales and broad spectrum antibiotic sales [10]. This analysis suggested that even if there was a potential causal association of antibiotic use with asthma risk, it did not appear to explain the world wide differences between countries. The potential involvement, if any, of antibiotics may be in the alteration of induction of immunity rather than the exposure per se, and involve a combination of the effects of infection and microbial exposure too.

\section{Pollen}

Exposure to allergenic pollen was assessed by exposures around the dates of early life [8] and did not appear to increase the risk of acquiring symptoms of respiratory allergy, and may even give some protection. Other studies have found that the symptom prevalence of hay fever and asthma tends to be lower in rural than in urban areas, and lowest among people living on farms [24-28], but this has not been consistently found outside Europe and USA, and was not studied in our analyses. The degree of consistency in the inverse associations suggests the possibility of a protective effect of pollen on allergy.

\section{Air pollution}

A weak inverse relationship was demonstrated between city-level particulate air pollution $\left(\mathrm{PM}_{10}\right)$ and symptoms of the three conditions, even after controlling for GNP which has a strong inverse association with air pollution [6]. Meta-analyses of data from countries with multiple centres found by contrast a consistent pattern of weak positive associations. These generally weak associations were in line with existing ecological evidence on the association between particulate air pollution and asthma. This finding is not incompatible with the extensive evidence from individual level studies that air pollution may aggravate existing asthma, since this may not have an important effect on prevalence. Short-term fluctuations in pollutant levels may have different effects from chronically high concentrations. Neither does it exclude a causal role for roadside exposure for which there is limited evidence. Higher self-reported exposure to truck traffic obtained as part of ISAAC Phase Three was associated with higher symptom prevalences [29].

\section{Climate}

As climate affects whole populations, ecological studies are ideally suited to examine the relationship between 
prevalence of diseases and climatic conditions between populations. In the worldwide analyses few significant associations were seen [16]. However, in ISAAC studies in two large continents with quite marked climate differences - Latin America [30] and Africa [31] - no relationship was observed for asthma symptoms prevalence with respect to latitude, altitude, humid/dry climate or other geographical aspects, suggesting that meteorological and geographic factors, individually, would not be able to explain the wide variability in the prevalence of asthma, rhinitis and eczema in the world. As the world becomes more affected by climate change there may be some regions such as Western Europe where prevalence of disease is affected by potentially modifiable factors including humidity and temperature [16], but at a global level our ecological analyses showed little effect.

\section{Is the ecological approach sound?}

The central ISAAC approach has been to study symptoms of disease between populations, which has naturally led to ecological analyses between symptom prevalences and potential environmental exposures. As Rose states, "the primary determinants of disease are mainly economic and social, and therefore its remedies must also be economic and social" [32], and this has been the thrust of the ISAAC approach. If the environment of populations is important in the occurrence of asthma, rhinoconjunctivitis and eczema, as the evidence suggests it is, analyses should be at the population environmental level. Thus ecological analyses are a most useful way to examine the effect of the social, economic and other aspects of the environment on health. As Marmot has argued, analyses of individual risk factors may be inappropriate if social environmental causes of illness are sought [33]. The ecological approach has been successful in suggesting hypotheses concerning possible causes of international patterns of cancer in the 1950s and 1960s, which were investigated in depth in further studies [34]. As some risk factors genuinely operate at the population level, either directly causing disease, or causing disease as effect modifiers or determinants of exposure to individual risk factors, the prediction of the health effects in an exposed population can be of primary importance [35].

Naturally these data must be interpreted with care. The potential problem with ecological studies is that the relationship between factors at an ecological level may not be the same as the relationship at an individual level. It cannot be assumed that exposure-disease associations in comparisons between populations necessarily represent associations at the individual level - the 'ecological fallacy' [36-38]. There may be several reasons for this, including population-level confounding (populations differ for many variables that cannot be included in the analysis), aggregation bias (grouping of disparate types of individuals), and misclassification bias. On the other hand, ecological studies are not susceptible to certain biases that can affect associations among individuals: for example, recall bias, when current disease influences memory of exposure, and reverse causality, if early symptoms lead to treatment (e.g. paracetamol) or behaviour change (e.g. smoking cessation by parents) that then appear to be adverse factors for the established disease. The ecological approach may be the only way to study the effect of whole population exposures, and the problems of interpreting individual-level data are perhaps less commonly appreciated.

Notwithstanding concerns about potential biases, the large number of countries, centres and children participating provides an opportunity to identify themes for further exploration relating to these three interrelated conditions. These analyses were undertaken to make ecological inferences about effects on population symptom prevalence rates, rather than biological inferences about effects on individual risks. In ISAAC Phase Three there was individual exposure ascertainment with a wider range of exposures providing the opportunity to conduct parallel individual and centre (population) level analyses, and further exploration of the ecological approach.

\section{Conclusion}

ISAAC has explored environmental factors at a population level which may relate to the prevalence of asthma, rhinoconjunctivitis and eczema while recognising the limitations of the ecological approach in causal inference at the individual level. Some global associations which could be explored by further research were positive associations between the prevalence of symptoms of asthma, rhinoconjunctivitis and eczema in populations and GNP, trans fatty acids, paracetamol, and women smoking and inverse associations between food of plant origin, pollen, immunisations, tuberculosis notifications, air pollution, and men smoking, and some showed mixed effects (antibiotics and climatic factors). While the global ecological approach has advantages, it may miss factors of importance within regions, and involving combinations of variables within or between regions. ISAAC Phase Three has extended research in the areas identified in this review using an environmental questionnaire which enables some of these hypotheses to be explored further with individual level as well as ecological analyses. Further studies could include randomised controlled trials of putative risk factors such as paracetamol exposure. Since these ecological studies took place, globalization has introduced further large environmental changes. Rapid environmental and lifestyle changes within whole societies offers potential opportunities for 
demonstrating the importance of community-wide determinants of ill-health, and provides a rationale for monitoring time trends in asthma and allergic diseases in diverse populations, as in Phase One centres that also participated in ISAAC Phase Three.

\begin{abstract}
Abbreviations
AIDS: Acquired Immune Deficiency Syndrome; BCG: Bacille Calmette-Guérin vaccination; DTP: Diphtheria, tetanus and pertussis vaccination; ISAAC: The International Study of Asthma and Allergies in Childhood; $\mathrm{PM}_{10}$ : Particulate matter with aerodynamic diameter < $10 \mu \mathrm{m}$; TB: Tuberculosis; Th1: T helper cell 1; WHO: World Health Organization.
\end{abstract}

\section{Acknowledgements}

The authors are indebted to the collaborators in the participating centres and all parents, children, teachers and other school staff who participated in the surveys. There are many field workers and funding agencies who supported data collection and national, regional and international meetings, including the meetings of the ISAAC Steering Committee. Unfortunately, these are too numerous to mention (they are acknowledged elsewhere) but the authors particularly wish to thank the funders who supported the ISAAC International Data Centre including the Health Research Council of New Zealand, the Asthma and Respiratory Foundation of New Zealand, the National Child Health Research Foundation, the Hawke's Bay Medical Research Foundation, the Waikato Medical Research Foundation, Glaxo Wellcome New Zealand and Astra New Zealand, as well as Glaxo Wellcome International Medical Affairs for finding the regional coordinating centres. The International Data Centre is now supported by a grant from the BUPA Foundation.

\section{ISAAC Phase One study group}

ISAAC Steering Committee: N Ait-Khaled (Union Internationale Contre la Tuberculose et les Maladies Respiratoires, Paris, France); G Anabwani (Princess Marina Hospital, Gaborone, Botswana); HR Anderson (St Georges, University of London and MRC Centre for Environment and Health, London, UK); MI Asher (Department of Paediatrics: Child and Youth Health, Faculty of Medical and Health Sciences, The University of Auckland, New Zealand); R Beasley (Medical Research Institute of New Zealand, Wellington, New Zealand): B Björkstén (National Institute of Environmental Medicine/IMM, Karolinska Institutet, Stockholm, Sweden); ML Burr (Department of Primary Care \& Public Health, Cardiff University Neuadd Meirionnydd, Cardiff, UK); J Crane (Wellington Asthma Research Group, Wellington School of Medicine, New Zealand); U Keil (Institut für Epidemiologie und Sozialmedizin, Westfälische Wilhelms Universität, Münster, Germany); CKW Lai (Department of Medicine and Therapeutics, The Chinese University of Hong Kong, SAR China); J Mallol (Department of Pediatric Respiratory Medicine, University of Santiago de Chile, Chile); F Martinez (Arizona Respiratory Center, University of Arizona, Tucson, Arizona, USA); EA Mitchell (Department of Paediatrics: Child and Youth Health, Faculty of Medical and Health Sciences, The University of Auckland, New Zealand); S Montefort (Department of Medicine, University of Malta, Malta); N Pearce (Centre for Public Health Research, Massey University, Wellington, New Zealand); CF Robertson (Murdoch Children's Research Institute, Melbourne, Australia); JR Shah (Jaslok Hospital \& Research Centre, Mumbai, India); B Sibbald, (University of Manchester, Manchester, UK); AW Stewart (Population Health, Faculty of Medical and Health Sciences, The University of Auckland, New Zealand); DP Strachan (Division of Community Health Sciences, St Georges Hospital Medical School, London, UK); E von Mutius (Dr von Haunerschen Kinderklinik de Universität München, Germany); SK Weiland* (Department of Epidemiology, University of Ulm, Germany); HC Williams (Centre for Evidence Based Dermatology, Nottingham University Hospital's Queen's Medical Centre, Nottingham, UK). ${ }^{*}$ Deceased

ISAAC International Data Centre: MI Asher, TO Clayton, P Ellwood, EA Mitchell, (Department of Paediatrics: Child and Youth Health, Faculty of Medical and Health Sciences, The University of Auckland, New Zealand); AW Stewart, (School of Population Health, Faculty of Medical and Health Sciences, The University of Auckland, New Zealand).

ISAAC Phase One Principal Investigators: Africa Algeria: A Bezzaoucha (Algiers); Ethiopia: K Melaku* (Addis Ababa), B Seyoum (Jima); Kenya: FO Esamai (Eldoret), JA Odhiambo* (Nairobi); Nigeria: BO Onadeko (Ibadan); South
Africa: H Nelson (Cape Town); Asia Pacific China: Y-Z Chen* (Beijing), K-H Chen (Chongqing), N-S Zhong (Guangzhou), M Bao-Shan (Shanghai), M-L Xiao (Wulumuqi); Hong Kong: C Lai* (Hong Kong 13-14 yr), YL Lau (Hong Kong 6-7 yr); Indonesia: Dr K Baratawidjaja* (Bandung); Japan: S Nishima (Fukuoka); Malaysia: KH Teh (Alor Setar), LW Yeong (lpoh), J de Bruyne* (Klang Valley), BS Quah (Kota Bharu), KW Chum (Muar); Philippines: F CuaLim (Metro Manilla); South Korea: S-I Lee* (Provincial Korea and Seoul); Singapore: B-W Lee (Singapore); Taiwan: K-H Hsieh* (deceased) (Taipei); Thailand: P Vichyanond* (Bangkok), M Trakultivakorn (Chiang Mai); Eastern Mediterranean Iran: M-R Masjedi* (Rasht and Tehran); Kuwait: JA al-Momen (Kuwait); Lebanon: FM Ramadan (Beirut); Oman: BMS Al Riyami (Al-Khod); Malta: S Montefort (Malta); Morocco: Z Bouayad* (Casablanca and Marrakech), A Bennis (Rabat); Pakistan: ZA Bhutta (Karachi); Latin America Argentina: N Salmun* (Buenos Aires and Rosario); Brazil: N Rosário (Curitiba), R Stein (Porto Alegre), PGM Bezerra (Recife), L de Freitas Souza (Salvador), D Solé* (Sao Paulo); Chile: I Sanchez (Central Santiago), L Amarales (Punta Arenas), E Cortez (South Santiago), MA Calvo (Valdivia); Costa Rica (ME SotoQuirós), Mexico: I Romieu (Cuernavaca); Panama: G Cukier (David-Panama); Paraguay: JA Guggiari-Chase (Asuncion); Peru: P Chiarella (Lima); Uruguay: D Holgado (Montevideo); North America Canada: MR Sears* (Hamilton), B Taylor (Saskatoon); USA: V Persky (Chicago [3]), GJ Redding (Seattle); Northern and Eastern Europe Albania: A Priftanji (Tirane); Estonia: M-A Riikjärv* (Narva and Tallinn); Finland: M Kajosaari (Helsinki), J Pekkanen* (Kuopio County), L Soininen (Lapland Area), TA Koivikko (Turku and Pori County); Georgia: N Khetsuriani (Kutaisi), A Gamkrelidze* (Tbilisi); Latvia: M Leja* (Riga and Rural Latvia); Poland: G Lis* (Krakow), A Brêborowicz (Poznan); Romania: D Dumitrascu (Cluj); Russia: RM Khaitov (Moscow); Sweden: N-I Kjellman (Linköping), T Foucard (Stockholm/Uppsala); Uzbekistan: T Aripova* (Samarkand and Tashkent); Oceania Australia: D Kennedy (Adelaide), CF Robertson* (Melbourne), L Landau (Perth), J Peat (Sydney 6-7 yr), A Bauman (Sydney 13-14 yr); New Zealand: Ml Asher* (Auckland), C Moyes (Bay of Plenty), P Pattemore (Christchurch), D Barry (Hawke's Bay), R Mackay (Nelson), J Crane (Wellington); Indian Subcontinent India: RM Maheshwari (Akola), MK Joshi (Bombay [16]), UA Pai (Bombay [17]), K Raghavan (Bombay [18]), VA Khatav (Borivali), L Kumar (Chandigarh), KC Jain (Jodhpur), TU Sukumaran (Kottayam), S Rajajee (Madras [2]), N Somu (Madras [3]), K Chopra (New Delhi [7]), G Jayaraj (Neyveli), PK Kar (Orissa), NM Hanumante (Pune); Western Europe Austria: J Riedler* (Salzburg), G Haidinger (Urfahr-Umgebung); Belgium: P Vermeire (Antwerp); Channel Islands: D Jeffs (Guernsey), CR Grainger (Jersey), France: D Charpin* (Marseilles), P Godard (Montpellier), A Taytard (Pessac), C Kopferschmitt (Strasbourg), I Annesi-Maesano (West Marne); Germany: A Kramer (Greifswald), U Keil* (Munster); Greece: C Gratziou (Athens); Isle of Man (PV Powell), Italy: S Bonini (Ascoli Piceno), E Bonci (Cosenza), F Rusconi (Cremona), M Biocca (Emilia-Romagna), L Chetoni (Empoli), E Chellini (Firenze), R Ronchetti (Frosinone), L Bisanti (Milano), F Forastiere* (Roma), E Renzoni (Siena), G Ciccone (Torino), S Piffer (Trento), A Boner (Verona), G Corbo (Viterbo); Portugal: FD Borges (Funchal), JE Rosado Pinto* (Lisbon), C Nunes (Portimão), JM Lopes dos Santos (Porto); Republic of Ireland: L Clancy (Rep of Ireland); Spain: RM Busquets (Barcelona), AD Rubio (Bilbao), AR Asensio (Cadiz), L García-Marcos* (Cartagena), A Arnedo-Pena (Castellon), F Guillén-Grima (Pamplona), MM Morales-Suárez-Varela (Valencia), A Blanco Quirós (Valladolid); United Kingdom: HR Anderson* (Anglia and Oxford, North East and Yorkshire, North Thames, North West, South and West, South Thames, Scotland, Trent, Wales, West Midlands), MH Shamssain (Sunderland), D Strachan (Surrey/Sussex).

*National Coordinator

\section{National Coordinators not identified above}

Chile: J Mallol; India: J Shah

\section{Author details}

'Department of Paediatrics: Child and Youth Health, The University of Auckland, Auckland, New Zealand. ${ }^{2}$ School of Population Health, The University of Auckland, Auckland, New Zealand. ${ }^{3}$ Department of Pediatric Respiratory Medicine, University of Santiago de Chile (USACH), Hospital El Pino, Santiago, Chile. ${ }^{4}$ Department of Medicine, University of Malta, Malta. ${ }^{5}$ Department of Medicine and Therapeutics, The Chinese University of Hong Kong, Hong Kong, SAR PR China. IInternational Union Against Tuberculosis Lung Diseases, Paris, France. ${ }^{7}$ Centre for Respiratory Diseases Research, Kenya Medical Research Institute (KEMRI), Nairobi, Kenya. ${ }^{8}$ Members listed at the end of the manuscript. 


\section{Authors' contributions}

IA drafted the manuscript. The named authors on the title page made a large contribution to the manuscript writing. All authors contributed data to the studies, and read, commented and approved the final manuscript.

\section{Authors' information}

Professor Innes Asher is Head of the Department of Paediatrics: Child and Youth Health at the University of Auckland and has been Chair of the ISAAC Steering Committee since its inception in 1991. Alistair Stewart is a senior Biostatistician at the University of Auckland and is a member of the ISAAC Steering Committee. Professor Javier Mallol is Head of the Department of Paediatric Respiratory Medicine at Hospital CRS El Pino, University of Santiago de Chile (USACH). Professor Mallol is the ISAAC Regional Coordinator for Latin America and is a member of the ISAAC Steering Committee. Professor Stephen Montefort is a Consultant Respiratory Physician and Professor of Medicine in the Department of Medicine, University of Malta. Professor Montefort is the ISAAC Regional Coordinator for the Eastern Mediterranean and is a member of the ISAAC Steering Committee. Professor Christopher Lai is an honorary clinical professor in the Department of Medicine and Therapeutics, the Chinese University of Hong Kong. Professor Lai is the ISAAC Regional Coordinator for the Asia-Pacific region and is a member of the ISAAC Steering Committee. Professor Nadia Ait-Khaled is Head of Asthma Division of the International Union Against Tuberculosis and Lung Disease (The Union). Professor Ait-Khaled is the ISAAC Regional Coordinator for French-speaking Africa and is a member of the ISAAC Steering Committee. Dr Joseph Odhiambo is based at the Centre for Respiratory Diseases Research, Kenya Medical Research Institute (KEMRI), Nairobi. Dr Odhiambo is the ISAAC Regional Coordinator for Englishspeaking Africa and is a member of the ISAAC Steering Committee.

\section{Competing interests}

The authors are co-authors on the ISAAC publications referred to in this article. They declare no competing interests.

Received: 30 October 2009

Accepted: 21 January 2010 Published: 21 January 2010

\section{References}

1. Asher M, Keil U, Anderson H, Beasley R, Crane J, Martinez F, Mitchell E, Pearce N, Sibbald B, Stewart A, et al: International Study of Asthma and Allergies in Childhood (ISAAC): rationale and methods. Eur Respir J 1995 8:483-491

2. ISAAC Steering Committee: Worldwide variations in the prevalence of asthma symptoms: the International Study of Asthma and Allergies in Childhood (ISAAC). Eur Respir J 1998, 12:315-335.

3. ISAAC Steering Committee: Worldwide variation in prevalence of symptoms of asthma, allergic rhinoconjunctivitis, and atopic eczema: ISAAC. Lancet 1998, 351:1225-1232.

4. Strachan D, Sibbald B, Weiland S, Ait-Khaled N, Anabwani G, Anderson H, Asher $M$, Beasley $R$, Bjorksten $B$, Burr $M$, et al: Worldwide variations in prevalence of symptoms of allergic rhinoconjunctivitis in children: the International Study of Asthma and Allergies in Childhood (ISAAC). Pediatr Allergy Immunol 1997, 8:161-176.

5. Williams H, Robertson C, Stewart A, Ait-Khaled N, Anabwani G, Anderson R, Asher I, Beasley R, Bjorksten B, Burr M, et al: Worldwide variations in the prevalence of symptoms of atopic eczema in the International Study of Asthma and Allergies in Childhood. J Allergy Clin Immunol 1999, 103:125-138

6. Anderson H, Ruggles R, Pandey K, Kapetanakis V, Lai CKW, Strachan D, Weiland S, the ISAAC Phase One Study Group: Ambient particulate pollution and the prevalence of asthma, rhinoconjunctivitis and eczema in children: Phase One of the International Study of Asthma and Allergies in Childhood (ISAAC). Occup Environ Med 2009, doi:10.1136/ oem.2009.048785.

7. Anderson HR, Poloniecki JD, Strachan DP, Beasley R, Bjorksten B, Asher MI, the ISAAC Phase One Study Group: Immunization and symptoms of atopic disease in children: results from the International Study of Asthma and Allergies in Childhood. Am J Public Health 2001, 91:1126-1129.

8. Burr M, Emberlin J, Treu R, Cheng S, Pearce N, the ISAAC Phase One Study Group: Pollen counts in relation to the prevalence of allergic rhinoconjunctivitis, asthma and atopic eczema in the International Study of Asthma and Allergies in Childhood (ISAAC). Clin Exp Allergy 2003, 33:1675-1680.

9. Ellwood P, Asher MI, Björkstén B, Burr M, Pearce N, Robertson CF, the ISAAC Phase One Study Group: Diet and asthma, allergic rhinoconjunctivitis and atopic eczema symptom prevalence: an ecological analysis of the International Study of Asthma and Allergies in Childhood (ISAAC) data. Eur Respir J 2001, 17:436-443.

10. Foliaki S, Nielsen SK, Björkstén B, Von Mutius E, Cheng S, Pearce N, the ISAAC Phase One Study Group: Antibiotic sales and the prevalence of symptoms of asthma, rhinitis, and eczema: The International Study of Asthma and Allergies in Childhood (ISAAC). Int J Epidemiol 2004, 33:558-563.

11. Mitchell EA, Stewart AW, on behalf of the ISAAC Phase One Study Group: The ecological relationship of tobacco smoking to the prevalence of symptoms of asthma and other atopic diseases in children: the International Study of Asthma and Allergies in Childhood (ISAAC). Eur Epidemiol 2001, 17:667-673.

12. Newson RB, Shaheen SO, Chinn S, Burney PG: Paracetamol sales and atopic disease in children and adults: an ecological analysis. Eur Respir J 2000, 16:817-823.

13. Shirtcliffe $P$, Weatherall $M$, Beasley $R$, on behalf of the ISAAC Phase One Study Group: An inverse correlation between estimated tuberculosis notification rates and asthma symptoms. Respirology 2002, 7:153-155.

14. Stewart AW, Mitchell EA, Pearce N, Strachan DP, Weiland SK, on behalf of the ISAAC Steering Committee: The relationship of per capita gross national product to the prevalence of symptoms of asthma and other atopic diseases in children (ISAAC). [see comments.]. Int J Epidemiol 2001, 30:173-179.

15. von Mutius E, Pearce N, Beasley R, Cheng S, von Ehrenstein O, Björkstén B, Weiland S, on behalf of the ISAAC Steering Committee: International patterns of tuberculosis and the prevalence of symptoms of asthma, rhinitis and eczema. Thorax 2000, 55:449-453.

16. Weiland SK, Husing A, Strachan DP, Rzehak P, Pearce N, the ISAAC Phase One Study Group: Climate and the prevalence of symptoms of asthma, allergic rhinitis, and atopic eczema in children. Occup Environ Med 2004, 61:609-615.

17. Weiland SK, von Mutius E, Husing A, Asher MI, on behalf of the ISAAC Steering Committee: Intake of trans fatty acids and prevalence of childhood asthma and allergies in Europe. ISAAC Steering Committee. Lancet 1999, 353:2040-2041.

18. Ellwood P, Williams H, Ait-Khaled N, Björkstén B, Robertson C, the ISAAC Phase Three Study Group: Translation of questions: The International Study of Asthma and Allergies in Childhood (ISAAC) experience. Int J Tuberc Lung Dis 2009, , 9: 1174-82.

19. Greenland S, Schlesselman JJ, Criqui MH: The fallacy of employing standardized regression coefficients and correlations as measures of effect. Am J Epidemiol 1986, 123:203-208.

20. Lai C, Beasley R, Crane J, Foliaki S, Shah J, Weiland S: Global variation in the prevalence and severity of asthma symptoms: Phase Three of the International Study of Asthma and Allergies in Childhood (ISAAC). Thorax 2009, 64(6):476-483.

21. Cooper PJ, Rodrigues LC, Cruz AA, Barreto ML: Asthma in Latin America: a public heath challenge and research opportunity. Allergy 2009, 64:5-17.

22. Björkstén B: Effects of intestinal microflora and the environment on the development of asthma and allergy. Springer Semin Immunopathol 2004, 25:257-270.

23. Beasley R, Clayton T, Crane J, von Mutius E, Lai CKW, Montefort S, Stewart A, for the ISAAC Phase Three Study Group: Association between paracetamol use in infancy and childhood, and risk of asthma, rhinoconjunctivitis, and eczema in children aged 6-7 years: analysis from Phase Three of the ISAAC programme. Lancet 2008, 372:1039-1048.

24. Åberg N: Asthma and allergic rhinitis in Swedish conscripts. Clin Exp Allergy 1989, 19:59-63.

25. Braun-Fahrlander C, Gassner M, Grize L, Neu U, Sennhauser FH, Varonier HS, Vuille JC, Wuthrich B: Prevalence of hay fever and allergic sensitization in farmer's children and their peers living in the same rural community. SCARPOL team. Swiss Study on Childhood Allergy and Respiratory Symptoms with Respect to Air Pollution. [see comment]. Clin Exp Allergy 1999, 29:28-34. 
26. Kilpel äinen $M$, Terho EO, Helenius $H$, Koskenvuo M: Farm environment in childhood prevents the development of allergies. [see comment]. Clin Exp Allergy 2000, 30:201-208.

27. Riedler J, Eder W, Oberfeld G, Schreuer M: Austrian children living on a farm have less hay fever, asthma and allergic sensitization. [see comment]. Clin Exp Allergy 2000, 30:194-200.

28. Von Ehrenstein OS, Von Mutius E, Illi S, Baumann L, Bohm O, von Kries R: Reduced risk of hay fever and asthma among children of farmers. [see comment]. Clin Exp Allergy 2000, 30:187-193.

29. Brunekreef B, Stewart AW, Anderson HR, Lai CKW, Strachan DP, Pearce NE, the ISAAC Phase Three Study Group: Self Reported Truck Traffic in Street of Residence and Symptoms of Asthma and Allergic Disease: a Global Relationship in ISAAC Phase Three. Environ Health Perspect 2009, 117:1791-1798.

30. Mallol J, Sole D, Asher I, Clayton T, Stein R, Soto-Quiroz M: Prevalence of asthma symptoms in Latin America: the International Study of Asthma and Allergies in Childhood (ISAAC). [comment]. Pediatr Pulmonol 2000, 30:439-444.

31. Ait-Khaled N, Odhiambo J, Pearce N, Adjoh KS, Maesano IA, Benhabyles B, Bouhayad Z, Bahati E, Camara L, Catteau C, et al: Prevalence of symptoms of asthma, rhinitis and eczema in 13- to 14-year-old children in Africa: the International Study of Asthma and Allergies in Childhood Phase III. Allergy 2007, 62:247-258.

32. Rose G: The strategy of preventive medicine Oxford: Oxford University Press 1992.

33. Marmot MG: Improvement of social environment to improve health. Lancet 1998, 351:57-60.

34. Pearce N: The ecological fallacy strikes back. [comment]. J Epidemiol Community Health 2000, 54:326-327.

35. Seiler FA, Alvarez JL: Is the "Ecological Fallacy" a fallacy?. Hum Ecol Risk Assess 2000, 6:921-941.

36. Greenland S, Morgenstern H: Ecological bias, confounding, and effect modification. [see comment][erratum appears in Int J Epidemiol 1991 Sep;20(3):824]. Int J Epidemiol 1989, 18:269-274.

37. Morgenstern $\mathrm{H}$ : Uses of ecologic analysis in epidemiologic research. Am J Public Health 1982, 72:1336-1344.

38. Morgenstern $\mathrm{H}$ : Ecologic studies in epidemiology: concepts, principles, and methods. Annu Rev Public Health 1995, 16:61-81.

doi:10.1186/1465-9921-11-8

Cite this article as: Asher et al: Which population level environmental factors are associated with asthma, rhinoconjunctivitis and eczema? Review of the ecological analyses of ISAAC Phase One. Respiratory Research 2010 11:8.

\section{Submit your next manuscript to BioMed Central and take full advantage of:}

- Convenient online submission

- Thorough peer review

- No space constraints or color figure charges

- Immediate publication on acceptance

- Inclusion in PubMed, CAS, Scopus and Google Scholar

- Research which is freely available for redistribution 